\begin{tabular}{|c|c|}
\hline & $\begin{array}{l}\text { International Journal of Trend in Scientific } \\
\text { Research and Development (IJTSRD) }\end{array}$ \\
\hline 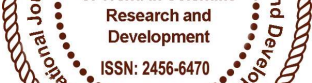 & International Open Access Journal \\
\hline 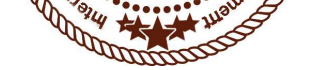 & ISSN No: 2456 - 6470 | www.ijtsrd.com | Volume - 2 | Issue - 2 \\
\hline
\end{tabular}

\title{
In vitro plant regeneration from hypocotyl explants of Rheum webbianum Royle
}

\author{
Sabreena Rashid, Zahoor A Kaloo, Seema Singh, Iram Bashir \\ Plant Tissue Culture Research Laboratory, Department of Botany, \\ University of Kashmir, Hazratbal, Srinagar, Jammu \& Kashmir, India
}

\section{ABSTRACT}

Rheum webbianum commonly known as "rhubarb" is a reputed medicinal plant belonging to family Polygonaceae. An attempt has been made to carry out the in vitro regeneration of this important medicinal plant species using hypocotyl segments as explants. Direct organogenesis occurred when the hypocotyl segments from the in vitro germinated seedlings were inoculated on MS medium containing different growth regulators at various concentrations and combinations. Cytokinins like BAP and $\mathrm{Kn}$ were found to be effective in shoot regeneration both individually as well as in combination with auxins like IAA, IBA and 2,4-D MS medium supplemented with BAP at a concentration of $2 \mathrm{mg} / \mathrm{l}$ in combination with IAA at a concentration of $3 \mathrm{mg} / \mathrm{l}$ was found to be the best medium for shoot regeneration. For rooting of regenerated shoots half strength MS medium supplemented with $0.5 \mathrm{mg} / 1$ IAA was found to be most effective.

Keywords: Organogenesis, hypocotyl, cytokinins

\section{Introduction}

Plants are valuable source of medicine and other pharmaceutical products and have been used by almost all the cultures from ancient times till date. Today medicinal plants are important to global economy (Srivastava et al., 1995) as approximately $85 \%$ of the traditional medicine preparations involve the use of plants or plant extracts (Vieira and Skorupa,
1993). Many traditional healing herbs and their parts have been shown to have medicinal value and can be used to prevent, or cure several human diseases (Dhar et al., 1999) like cancer, AIDS, malaria, cardiovascular diseases and neurological disorders. Some of the active components of plants like podophyllotoxin, campotothecin, taxol, vincristine etc. are used to develop drugs against cancer (Pezzuto, 1996). In the past few decades there has been an increased intrest in the study and use of medicinal plants in health care (Hoareau and Da Silva, 1999). In a wider context, there is a growing demand for plant based medicine in the national and international markets. So the genetic diversity of the medicinal plants of the world is getting endangered at an alarming rate because of the ruinous harvesting for production of medicines. Due to these threats, most of the important plant species of reputed medicinal value growing in Kashmir Himalaya including Corydalis cashmeriana, Rheum webbianum Saussurea costus, Arisaema jacquemontii, Lavatera kashmiriana, Taxus wallichiana, Hyoscyamus niger etc have become extinct. Hence immediate focus is required on the issues like conservation and sustainable use of these plants in order to save this precious diversity from vanishing. As the conventional methods of plant propagation take a long time for multiplication because of low rate fruit set, poor seed germination, etc. there is a need for an alternative method for rapid multiplication and propagation of these plants. Tissue culture techniques provide an efficient means for 
rapid propagation and conservation of these valuable medicinal plants. Plant tissue culture techniques have been increasingly applied to many medicinal plants in particular for mass propagation, conservation of germplasm, study and production of bioactive compounds and genetic improvement. It is an attractive and alternative approach to the traditional plantation methods as it offers a controlled supply of biochemicals independent of plant availability and more consistent product quality (Sajc et al., 2000). The in vitro propagated medicinal plants furnish a ready source of uniform, sterile, and compatible plant material for biochemical characterization and identification of active constituents.

Rheum webbianum is a perennial herb belonging to family Polygonaceae. The medicinal importance of this plant species is mainly due various secondary metabolites. The main secondary metabolites present in Rheum webbianum to which it owes its medicinal importance are anthraquinones like rhein, emodin, aloe-emodin, physcion and chrysophanol (Tayade et al., 2012). Since the anthraquinones get accumulated mainly in the rhizomes, whole plant is to be uprooted to extract the active component which in turn leads to the overexploitation of the plant species. So the present study was carried to develop an efficient regeneration system for its conservation and sustainable use.

\section{Materials and Methods:}

Seeds collected from the plants growing in Kashmir University Botanical Garden were kept in water overnight and then thoroughly washed under running tap water with detergent labolene and surfactant tween-20. In order to decrease the contamination rate the seeds were kept in a solution of $1 \%$ mercuric chloride for 15 minutes. After draining the solution the seeds were washed 3-4 times thoroughly with autoclaved water so as to remove the last traces of the chemical sterilant. Seed germination occurred on MS hormone free medium within a time period of one week. The hypocotyl segments of the seeds were excised in laminar air flow hood and were then inoculated on MS medium augmented with different concentrations of growth regulators. The $\mathrm{pH}$ of the medium adjusted to 5.8 prior to gelling with agar was dispensed in culture tubes and flasks and sterilized by autoclaving at $121^{\circ} \mathrm{C}$ temperature and $15 \mathrm{lbs}$ pressure for 15 minutes. The cultures were incubated under controlled conditions in the culture room under the regime of $16 \mathrm{~h}$ light period (500-3000 lux) and $8 \mathrm{~h}$ dark period and temperature of $22 \pm 4 \mathrm{C}^{\circ}$.

\section{Statistical Analysis:}

Data was analyzed using SPSS 16 s0ftware. ANNOVA was used to test the difference between different treatments. Tukey's multiple comparison test was used to compare all the treatments and difference between individual means at $\mathrm{p} \leq 0.05$.

\section{Results}

\section{Shoot regeneration}

Direct organogenesis occurred when the hypocotyl segments from the in vitro germinated seedlings were inoculated on MS medium containing different growth regulators at various concentrations and combinations. Various growth regulators were used to supplement MS medium to induce shoot regeneration in hypocotyl explants. Table 1 depicts that BAP was found to be effective to induce adventitious shooting in the cultures (Fig 1). When used individually at a concentration of $2 \mathrm{mg} / 1$ it was found to induce regeneration of $6.8 \pm 0.58$ shoots with a mean shoot length of $4.9 \pm 0.35 \mathrm{~cm}$ within 18 days in $80 \%$ cultures (Fig 1a). In order to assess the effect of auxin cytokinin combinations on shoot regeneration the medium was augmented with a range of concentrations of IAA ranging from $1 \mathrm{mg} / 1$ to $5 \mathrm{mg} / 1$. Out of all combinations tried BAP at a concentration of $2 \mathrm{mg} / 1$ in combination with IAA at a concentration of $3 \mathrm{mg} / \mathrm{l}$ was found to be the best medium in terms of shoot regeneration where on the hypocotyl segments regenerated $7.4 \pm 0.40$ shoots with a mean shoot length of $4.5 \pm 0.13 \mathrm{~cm}$ within 18 days in $100 \%$ cultures (Fig 1b). $2 \mathrm{mg} / 1 \mathrm{BAP}$ combined with $1 \mathrm{mg} / 1 \mathrm{IAA}$ was also found to be a good auxin cytokinin combination on which $7.4 \pm 0.92$ shoots with a mean shoot length of $4.5 \pm 0.31 \mathrm{~cm}$ were regenerated within 19 days with a percent response of 90 (Fig 1c). When the hypocotyl segments were inoculated on MS medium supplemented with equal ratio of BAP and IAA concentrations i.e, $2 \mathrm{mg} / \mathrm{l}$ each both the plant response $(4.4 \pm 0.4$ shoots with a mean length of $3.3 \pm 0.30 \mathrm{~cm})$ as well as culture response $(70 \%)$ diminished as compared to other two combinations(Fig 1d). 
International Journal of Trend in Scientific Research and Development (IJTSRD) ISSN: 2456-6470

Table:1 Effect of different hormones on shoot regeneration from hypocotyl explants:

\begin{tabular}{|l|l|l|l|l|l|l|}
\hline & MS $+\mathrm{B}_{2} \mathrm{I}_{3}$ & $\mathbf{M S}+\mathrm{B}_{2} \mathrm{I}_{2}$ & $\mathbf{M S}+\mathrm{B}_{2} \mathrm{I}_{1}$ & $\mathbf{M S}+\mathrm{B}_{2}$ & $\mathbf{F}$ Value & $\mathrm{P}$ Value \\
\hline Mean no. of shoots $\pm \mathbf{S E}$ & $7.4 \pm 0.40^{\mathrm{a}}$ & $4.4 \pm 0.40^{\mathrm{b}}$ & $7.4 \pm 0.92^{\mathrm{a}}$ & $6.8 \pm 0.58^{\mathrm{ab}}$ & 5.368 & 0.009 \\
\hline Mean length of shoots (cm) $\pm \mathbf{S E}$ & $\begin{array}{l}4.5 \pm 0.13 \\
\mathrm{a}\end{array}$ & $\begin{array}{l}3.3 \pm 0.30 \\
\mathrm{ab}\end{array}$ & $4.5 \pm 0.31^{\mathrm{b}}$ & $4.9 \pm 0.35^{\mathrm{b}}$ & 8.919 & 0.001 \\
\hline Mean no. of days taken & $14^{\mathrm{a}}$ & $15^{\mathrm{a}}$ & $19^{\mathrm{b}}$ & $18^{\mathrm{b}}$ & 3.105 & 0.056 \\
\hline Percent culture response & $100^{\mathrm{a}}$ & $70^{\mathrm{b}}$ & $90^{\mathrm{c}}$ & $80^{\mathrm{d}}$ & 7.913 & 0.005 \\
\hline
\end{tabular}

(10 replicates per treatment)

Mean \pm Standard error of 10 replicates

Mean values were compared using Tukey's multiple comparison test. The means followed by the same alphabets are not statistically different.

\section{Shoot Multiplication:}

Shoots regenerated from the hypocotyl segments multiplied on MS medium supplemented with varying concentrations of different growth regulators(Fig 2) (Table 2). When the shoots from MS medium containing $2 \mathrm{mg} / \mathrm{l} \mathrm{IAA}$ and $1 \mathrm{mg} / \mathrm{Kn}$ were subcultured on MS medium containing $1 \mathrm{mg} / 1$ 2,4-D and 2mg/l Kn, the average shoot number and length increased. Prior to sub culturing the average number and length of the shoots was $2.8 \pm 0.2$ and $3.5 \pm 0.26 \mathrm{~cm}$ respectively (Fig $2 \mathrm{a}$ ). However, after sub culturing the average shoot number was increased to $5.4 \pm 0.4$ and the average shoot length was increased to $4.9 \pm 0.32 \mathrm{~cm}$ (Fig. 2b). Subculturing of shoots obtained on MS medium fortified with 3mg/1 BAP and 1mg/1 2,4-D (Fig. 2c) to the same medium where IBA at a concentration of $1 \mathrm{mg} / \mathrm{l}$ was used as a source of auxin and BAP concentration dropped to $1.4 \mathrm{mg} / 1 \mathrm{led}$ to the rapid multiplication (Fig 2d). The average shoot number was found to increase from $3.4 \pm 0.4$ to $5.8 \pm 0.58$ and the average shoot length from $2.4 \pm 0.21 \mathrm{~cm}$ to $3.5 \pm 0.28 \mathrm{~cm}$.

Table: 2 Effect of different hormones on shoot multiplication from hypocotyl explants:

\begin{tabular}{|c|c|c|c|c|c|c|}
\hline & $\mathbf{M S}+\mathrm{I}_{2} \mathrm{~K}_{1}$ & $\mathrm{MS}+\mathrm{D}_{1} \mathrm{~K}_{2}$ & $\mathrm{MS}+\mathrm{B}_{3} \mathrm{D}_{1}$ & $\mathrm{MS}+\mathrm{B}_{1.4} \mathrm{IB}$ & F Value & P Value \\
\hline Mean no. of shoots $\pm \mathrm{SE}$ & $2.8 \pm 0.20^{\mathrm{a}}$ & $5.4 \pm 0.40^{b}$ & $3.4 \pm 0.40^{\mathrm{a}}$ & $5.8 \pm 0.58^{b}$ & 12.400 & 0.000 \\
\hline Mean length of shoots $(\mathrm{cm}) \pm \mathrm{SE}$ & $3.5 \pm 0.26^{\mathrm{ab}}$ & $4.9 \pm 0.32^{\mathrm{a}}$ & $2.4 \pm 0.21^{b}$ & $3.5 \pm 0.28^{\mathrm{ab}}$ & 5.597 & 0.008 \\
\hline Mean no. of days taken & $10^{\mathrm{a}}$ & $18^{\mathrm{b}}$ & $11^{\mathrm{a}}$ & $16^{\mathrm{ab}}$ & 9.475 & 0.001 \\
\hline Percent culture response & $30^{\mathrm{a}}$ & $80^{b}$ & $50^{\mathrm{c}}$ & $70^{\mathrm{d}}$ & 6.532 & 0.004 \\
\hline
\end{tabular}

(10 replicates per treatment)

Mean \pm Standard error of 10 replicates

Mean values were compared using Tukey's multiple comparison test. The means followed by the same alphabets are not statistically different.

\section{Rooting of regenerated shoots}

Rooting was achieved by reducing the salt strength of MS medium to half (Fig 3) and fortifying it with $0.5 \mathrm{mg} / 1$ IAA. $3.2 \pm 0.32$ roots were produced with a mean root length of $0.95 \pm 0.15 \mathrm{~cm}$ in $50 \%$ cultures within 43 days 
(Fig 3a). However, IBA at a concentration of $2 \mathrm{mg} / 1$ proved effective to produce $2.6 \pm 0.24$ roots with mean root length of $2.65 \pm 0.10 \mathrm{~cm}$ in $30 \%$ cultures within 46 days (Fig $3 b$ ).

\section{Transplantation}

For acclimatization 43 days old plantlets with well developed shoots as well as roots were taken out of the culture vials. The medium adhering to the basal portion of plantlets was washed off with double distilled water. After washing they were transferred to jiffy pots containing autoclaved soil and maintained under controlled conditions of temperature $\left(22 \pm 4^{\circ} \mathrm{C}\right)$ and relative humidity $(60 \%)$ in green house. These plantlets were watered at regular intervals(Fig $3 c \& d)$.

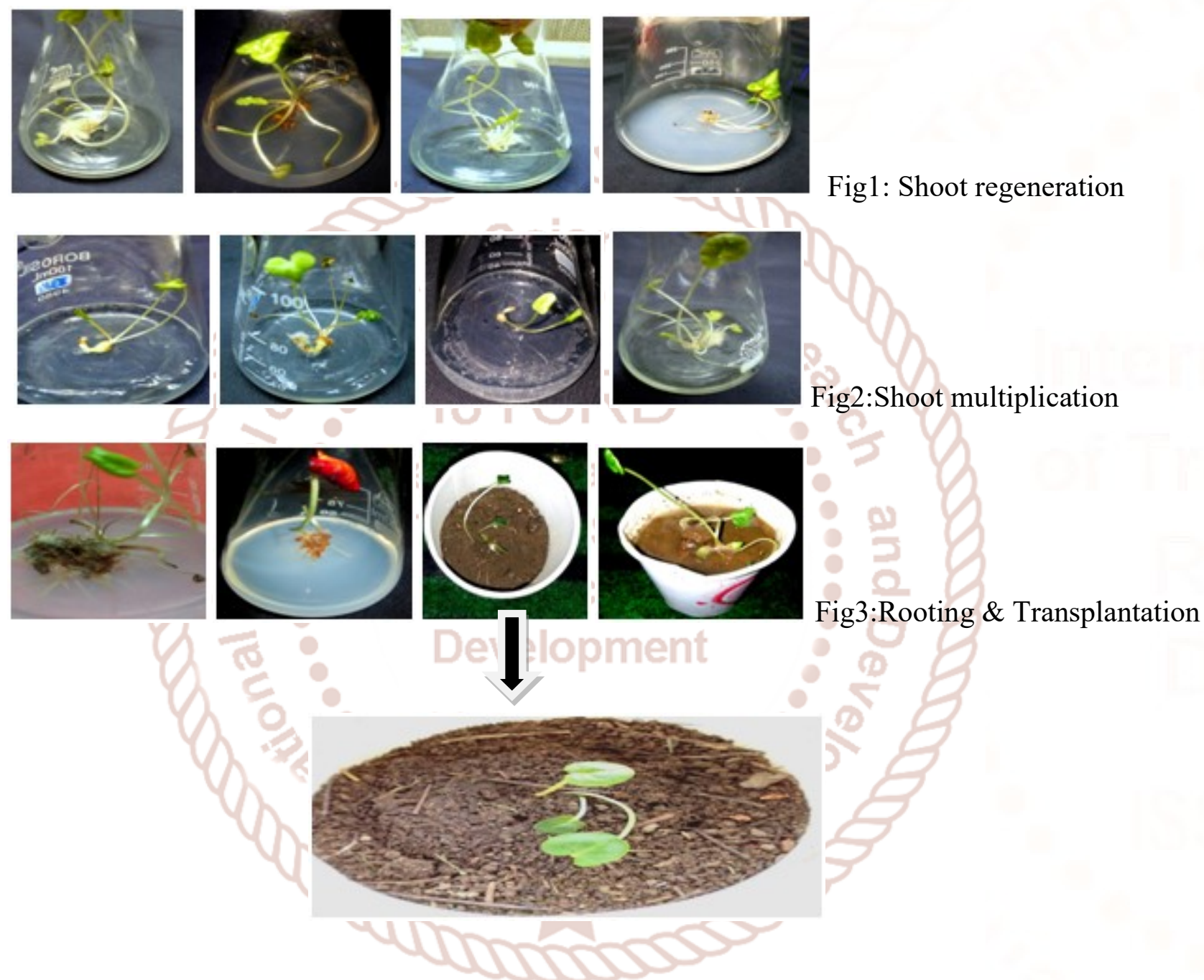

\section{Discussion}

The results reveal that the hypocotyls have a good regeneration potential and can be used for large scale propagation of this plant species within minimum time duration. In fact hypocotyls have been used as explants by many workers while carrying out tissue culture studies in the plants of family Polygonaceae especially in Fagopyrum and almost all of them got positive results for shoot regeneration either through callusing or directly. Culafic et al. (1987) used hypocotyls as explants in case of Rumex acetosella and Rumex acetosa and obtained indirect shoot regeneration on a medium containing high BAP to IAA ratio. Similar results were got by Adachi et al. (1989) while culturing hypocotyls of Fagopyrum esculentum.. Hong et al. (1999) got indirect shoot regeneration in Fagopyrum esculentum using MS medium supplemented with $2 \mathrm{mg} / 1$ 2,4-D and $1.5 \mathrm{mg} / 1$ BAP for callus induction and $2 \mathrm{mg} / \mathrm{l} \mathrm{Kn}$ and $1 \mathrm{mg} / \mathrm{l}$ BAP for shoot regeneration. In fact there are so many reports of indirect shoot regeneration from hypocotyl explants in family Polygonaceae. According to Moumou et al. (1992), Yong-hai et al. (2006), Chen et al. (2006), Hong and Qin (2006) 2,4-D either alone or in combination with BAP is preferable for callus 
induction in case of Fagopyrum. However, our results got for direct regeneration from hypocotyls are supported by those of Woo et al. (1997). They also got direct shoot formation in Fagopyrum esculentum and Fagopyrum homotropicum on a medium containing varied concentrations of IAA, BAP and 2,4-D.

\section{REFRENCES}

1) Srivastava, J., Lambert, J., Vietmeyer, N. (1995) Medicinal plants: an expanding role in development. World Bank technical paper no. 320.

2) Dhar, U., Rawal, R.S., Samant, S.S., Airi, S., Upreti, J. (1999) People's participation in Himalayan biodiversity conservation: a practical approach. Current Science. 76: 36-40.

3) Pezzuto, J. (1996) Taxol production in plant cell culture comes of age. Nature Biotechnology. 14: 1083.

4) Hoareau, L., DaSilva, E. (1999) Medicinal plants: a re-emerging health aid. Electronic Journal of Biotechnology. 2: 56-70.

5) Sajc, L., Grubisic, D., Vunjak-Novakovic, G. (2000) Bioreactors for plant engineering:/an outlook for further research. Biochemical Engineering. 4: 89-99.

6) Tayade, A., Dhar, P., Ballabh, B., Kumar, R., Chaurasia, O.P., Bhatt, R.P., Srivastava. (2012) Rheum webbianum Royle: a potential medicinal plant from trans-himalayan cold deserts of Ladakh, India.

7) Culafic, L., Budimir, S., Vujicic, R., Neskovic, M. (1987) Induction of somatic embryogenesis and embryo development in Rumex acetosella L. Plant Cell, Tissue and Organ Culture. 11:133-139.

8) Adachi, T., Yamaguchi, A., Miike, Y., Hoffmann, F. (1989) Plant regeneration from protoplasts of common buckwheat (Fagopyrum esculentum). Plant Cell Reports. 8: 247-250.

9) Hong, J., Jain-guo, H., Hong-Jun, M.A., Jing-fen, J.I.A. (1999). The tissue culture and regeneration of buckwheat (Fagopyrum esculemtum Moench.) Biotechnology institute, Northwest University, Xi'an 71: 69.

10) Moumou, Y., Vasseur, J., Trotin, F., Dubois, J. (1992) Catechin production by callus cultures of Fagopyrum esculentum. Phytochemistry. 31:12391241.

11) Yong-Hai, L., Le, Y., Weihua, H., Xain-en, L., Chao, W., Hai-bin, W. (2006) Study on germination condition and induction of callus in tartary buckwheat. Journal of Hunan Agricultural University. 1: 03.

12) Chen, L.H., Xu, Z. Q. (2006). Tissue culture and high-frequency plant regeneration of buckwheat (Fagopyrum esculentum Moench) Journal of Molecular Cell Biology. 39: 445.

13) Hong, C.L., Qin, X.Z. (2006) Tissue culture and high-frequency plant regeneration of buckwheat (Fagopyrum esculentum Moench. Journal of Molecular Cell Biology. 39: 445-52.

14) Woo, S.H., Jong, S.K., Adachi, T. (1997) Plant regeneration from hypocotyl of common (Fagopyrum esculentum) and wild annual buckwheat (F. homotropicum). Sabrao. 29: 97102. 